\title{
Two new species of nocturnal bees of the genus Megalopta (Hymenoptera: Halictidae) with keys to species
}

\author{
Victor H. Gonzalez ${ }^{1}$, Terry Griswold ${ }^{1} \&$ Ricardo Ayala ${ }^{2}$ \\ 1. USDA-ARS, Bee Biology and Systematics Laboratory, Utah State University, Logan, UT, 84322-5310, USA; \\ victorgonzab@gmail.com, Terry.Griswold@ars.usda.gov \\ 2. Estación de Biología Chamela, Instituto de Biología, Universidad Nacional Autónoma de México. Apartado Postal 21, \\ San Patricio Jalisco, 48980 México; rayala@ibiologia.unam.mx
}

Received 08-V-2009. C Corrected 20-IX-2009. Accepted 20-X-2009.

\begin{abstract}
Megalopta Smith, 1853, is a Neotropical genus of nocturnal or crepuscular bees. Two subgenera are recognized with most of its nearly 30 species placed in the nominate subgenus. Species of Megalopta s. str. are more commonly collected than species of Noctoraptor Engel et al. 1997, all presumably parasites of Megalopta s. str. Two new species of Megalopta are described here: M. (Megalopta) tetewana, n. sp., from Mexico and $M$. (Noctoraptor) huaoranii, n. sp., from Ecuador. Identification keys to the Central American species of Megalopta s. str. and the species of the parasitic subgenus Noctoraptor are presented. Rev. Biol. Trop. 58 (1): 255-263. Epub 2010 March 01.
\end{abstract}

Key words: Augochlorini, Apoidea, parasites, keys, systematics.

Megalopta Smith, 1853, is a Neotropical genus of nocturnal or crepuscular bees. Two subgenera are recognized with most of its nearly 30 species placed in the nominate subgenus (Engel 2000, Moure 2007, Santos \& Silveira 2009). Species of Megalopta s. str. are social wood-nesters (Wcislo et al. 2004) and are more commonly collected than species of Noctoraptor Engel et al. 1997, all presumably parasites of Megalopta s. str.

Presently, only three species of Megalopta s. str. are known from Central America, including Mexico: M. atra Engel, 2006, M. centralis Friese, 1926, and M. genalis MeadeWaldo, 1916; the first is only known from western Panama and Costa Rica whereas the latter two range south into South America (Engel 2006). The four species of Noctoraptor are only known from a few specimens collected in Panama (M. byroni Engel et al. 1997),
Guyana (M. furunculosa Hinojosa-Díaz \& Engel 2003), Ecuador (M. noctifurax Engel et al. 1997), and southeastern Brazil (M. atlantica Santos \& Silveira 2009). Despite several years of intensive surveys in Panama, few specimens of $M$. byroni have been collected in light traps or from nests of $M$. genalis and M. centralis (e.g., $\sim 1 \%$ of nearly 500 nests studied between 1998 and 2006; see Wcislo et al. 2004, Biani \& Wcislo 2007). The remaining species are only known from the holotype (Engel et al. 1997, Hinojosa-Díaz \& Engel 2003, Santos \& Silveira 2009).

Herein we describe and illustrate a new species of Megalopta s. str. from Mexico and a new species of the subgenus Noctoraptor from Ecuador. We also provide identification keys to the species of Megalopta s. str. from Central America, including Mexico, and the species of Noctoraptor. 


\section{MATERIAL AND METHODS}

The morphological description and illustrations were made using a Leica MZ12 stereomicroscope. Morphological terminology follows that of Michener (2007). Abbreviations used in the descriptions are: F, S, T, OD and PW for antennal flageller segment, metasomal sternum and tergum, ocellar diameter, and puncture diameter, respectively. Type specimens are deposited in the U.S. National Pollinating Insects Collection, Bee Biology and Systematics Laboratory, Utah State University, Logan, UT (BBSL), the insect collection of the Estación de Biología Chamela, Universidad Nacional Autónoma de México, Mexico (EBCC), and the entomological collection "Padre Jesus Santiago Moure" do Departamento de Zoologia da Universidade Federal do Paraná, Curitiba, Brazil (DZUP).

The distribution map of M. tetewana $\mathrm{n}$. sp. and $M$. centralis in Central America was generated with ArcMap 9.3, using the geographic data taken from labels of examined specimens deposited in BBSL, EBCC and in the following US institutions: American Museum of Natural History, New York (records from www. discoverlife.org); California Academy of Sciences, San Francisco, California (CAS); Snow Entomological Museum, University of Kansas, Lawrence, Kansas (SEM).

\section{Megalopta (Megalopta) tetewana $\mathbf{n}$. sp.} (Fig. 2-11): Ayala 1989: 408, 463; 2004: 202.

Diagnosis. Among Central American species, $M$. tetewana $\mathrm{n}$. sp. is similar to $M$. centralis in its male genitalia, body size, color, and the smooth and shiny, not striate, basal area of the propodeum. However, both sexes of M. tetewana $\mathrm{n}$. sp. can be reliably separated from $M$. centralis by the weaker and sparser punctures on scutum, scutellum and metanotum (contrasted in Fig. 1 and 2), and the predominantly light brown mesepisternum, scutum, scutellum, and metanotum. Additionally, normal-headed females (without genal spines or projections) of $M$. tetewana $\mathrm{n}$. sp. can be recognized by the stronger lateral and dorsal carinae of the pronotum.

Female. [normal-headed bee, without genal spines or projections] Body length $10.3 \mathrm{~mm}$; forewing length $9.2 \mathrm{~mm}$. Structure. Head about as long as wide; mandible curved toward apical third, with two strong apical teeth, upper tooth about half as long as lower, outer ridge not as strong as internal ridge; labrum with medial area prominent, lateral margins elevated, delimited by a sublateral furrow, basal area medially with weak elevation; clypeus $2.0 \mathrm{x}$ broader than long, with distal third projecting below lower tangent of compound eye; supraclypeal and interalveolar area elevated with respect to clypeus; interalveolar distance $0.8 \mathrm{x}$ shorter than alveolocular distance; interocellar distance about 2.0x longer than ocellocular distance; vertex elevated over superior margin of ocular orbit; occipital area rounded; scape 6.0x longer than broad, reaching or hardly exceeding superior margin of lateral ocellus; pedicel as long as broad, F1 longer than broad, F2 shorter than F1 or F3, F3-F9 each longer than broad, longer than F1; F10 longest; compound eye about $2.3 \mathrm{x}$ longer than wide, $1.4 \mathrm{x}$ broader than maximum width of gena in lateral view. Pronotum with strong lateral and dorsal carinae, posterolateral angle strongly carinate; scutellum flat, in same plane as scutum in profile view; inner hind tibial spur pectinate, with 4 teeth (not including apex as tooth). Coloration. Head with metallic green reflections except following parts light brown to yellow: mandible (except for black apex), labrum, clypeus, supraclypeal area, antenna, and hypostomal area. Mesosoma light brown, slightly darker than metasoma, with weak metallic green reflections on scutum, scutellum, metanotum, mesepisternum, hypoepimeral area, and sides of propodeum; wings yellowish, veins and stigma light brown, except for vein $R$ dark brown. Metasomal terga and sterna without metallic reflections. Pubescence. Head and mesosoma with two types of hairs; long, sparse (1.5-2.0x OD), erect simple or poorly branched hairs and short, denser $(\leq 0.5 \mathrm{x}$ OD), semi-erect, 

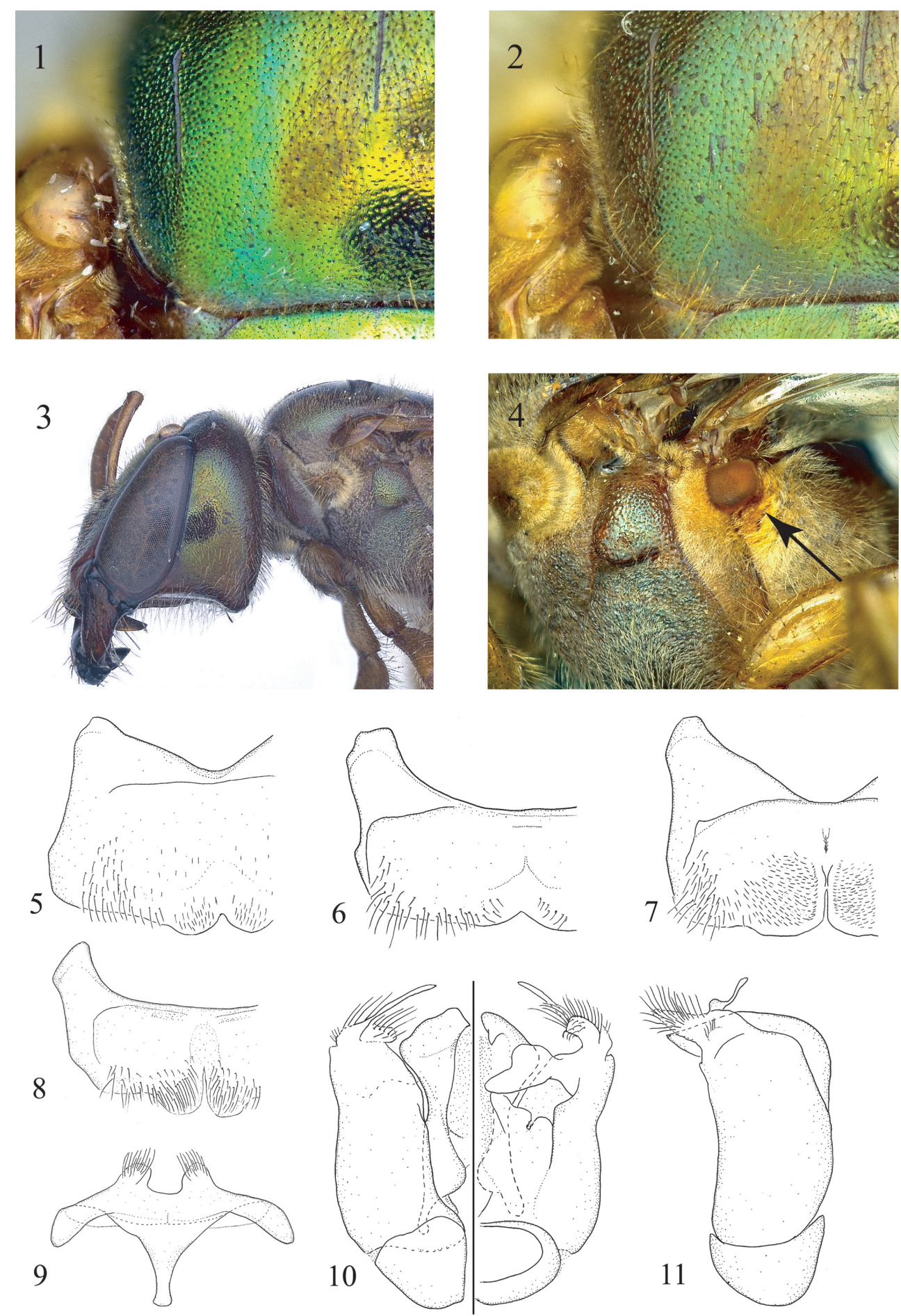

Figs. 1-11. Megalopta centralis (1) and M. tetewana n. sp. (2-11). 1,2, scutum of female. 3, macrocephalic female in profile. 4, male metepisternal organ indicated by the arrow. 5-11, male S3, S4, S5, S6, S7+S8, and genital capsule in dorsal (left half), ventral (right half), and profile views. 
golden to pale branched hairs; face except for distal half of clypeus, vertex, upper gena, mesepisternum dorsally, scutum, scutellum and metanotum with light brown erect hairs; remaining areas of head and mesosoma (including legs) with erect golden to pale hairs. Short, dense plumose hairs on pronotal lobe, metepisternum and lateral areas of propodeum. Erect hairs longer on distal half of clypeus, hypostomal area, and mesepisternum, sides of propodeum and metanotum; semierect hairs sparse on disc of scutum and hypoepimeral area; basal area of propodeum hairless. Terga with simple, semierect, short $(\leq 0.5 \mathrm{x}$ OD), golden hairs; $\mathrm{T} 1$ with long (1.0x OD), erect golden hairs on anterior surface; disc of T1 and T2, with sparse, erect, golden hairs, more abundant on T3 to T5; sterna with longer (2.0x OD), simple, pale, apically hooked or curly hairs. Punctation. Clypeus and supraclypeal area smooth and shiny, with few sparse punctures (2-4x PW); remaining areas of face, vertex and gena densely punctate; punctures finer and sparser on gena, integument otherwise smooth; hypostomal area weakly imbricate between sparse punctures. Pronotum laterally striate. Sides of scutum with denser (1-2x PW) and stronger punctures than on disc, integument largely smooth and shiny between punctures (Fig. 2). Scutellum with finer punctures that on scutum, integument smooth between punctures. Metanotum minutely, more densely punctate than on scutellum, integument otherwise smooth. Preomaular area striate, mesepisternum otherwise strongly, densely punctate; hypoepimeral area strongly punctate (1-2x PW), integument otherwise smooth and shiny; metepisternum densely punctate, almost granulate. Basal area of propodeum nearly smooth and shiny, not striate; remaining areas of propodeum minutely and densely punctate, integument smooth and shiny between punctures. Dorsal surface of T1 and T2 smooth and shiny between fine, sparse punctures; T3 to T6 with stronger punctures, especially on apical terga, integument weakly imbricate between punctures; sterna more strongly punctate and imbricate between punctures than on terga, especially on S2 and S3.
Male. As described for female, except for usual sexual characters and as follows: Body length $10.0 \mathrm{~mm}$; forewing length $9.2 \mathrm{~mm}$. Clypeus slightly wider than long, distal half yellowish or pale; interalveolar distance $1.3 \mathrm{x}$ greater than alveolocellar distance; interocellar distance about 4.0x longer than ocellocular distance; vertex slightly elevated on posterior margin of ocelli; scape 4.0x longer than wide, not reaching upper level of median ocellus, anterior face yellowish or pale; F1 shortest, F11 longest, F2-F11 each longer than broad; compound eye about 1.9x longer than wide, $2.5 \mathrm{x}$ broader than maximum width of gena. Pronotum with lateral carina not as strong as in female. Pronotal lobe and metepisternum with abundant dense, pale tomentum (integument not visible among hairs). Posterodorsal area of metepisternum with distinct, opaque, spongy structure (Fig. 4). S3-S8 and genital capsule as in Figs. 5-11.

Variation. As in the females of other species of Megalopta s. str., head size varies dramatically, including the presence or absence of a genal projection (Fig. 3), and a blunt, subapical tooth in the elongated mandibles. In some paratypes, the hind tibial spur has five teeth and the trochanter and femora are more yellow than the holotype.

Holotype. Female (normal-headed individual). MEXICO: Jalisco, Chamela, 1/8-X1985. F.D. Parker, T. Griswold (EBCC).

Paratypes. 172 females and 30 males from Jalisco, except for: Careyes: 1Q, 19-III1997, F. Parker. Cuitzmala: 1O, 28-II-1989, 1Q, 26-I-1990, E. Ramírez. Estación de Biología Chamela: 4Q, 26-II-1985; 3Q, 10-IV-1985; 1Q, 6-VII-1985; 10', 4-XI-1985; 1ᄋ, 4-XII1985; 19, 1-IX-1985, R. Ayala. 19, 19-IV-

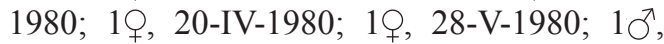
4-XII-1981; 1, 26-VII-1982; 10 ', 6-X-1982;

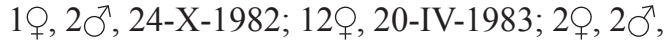
24-XII-1983; 1Q, 16-I-1991; 1ᄋ, 25-II-1991, S.H. Bullock. 10Q, 3ठ, 26/30-IX-1985; 41Q,

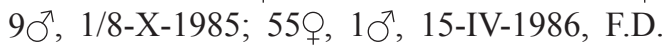


Parker \& T. Griswold. 13O, 50 , 25-IX-1985, C.D. Michener. 1Q, 10`, 25-IV-1989; 1Q, 12-V1989, E. Ramírez. 1O, 30-IX-1985; 10, 2-X1985; 6ᄋ, 5-X-1985; 2ᄋ, 6-X-1985, J. Rozen. 1q, 12-IX-1985; 1ᄋ, 2-X-1985; 4ㅇ, $1 \overbrace{}^{\top}$, 24-X-1985; 1Q, 10, 14-XII-1985, R.A. Usela. Nayarit, San Blas: 1\%, 10, 31-IX-1966, G. Bohart (BBSL, DZUP, EBCC).

Etymology. The specific name refers to Tetewa, the goddess of fertility of the Cora indigenous group that inhabits the Sierra del Nayar, between the Mexican states of Nayarit, Jalisco and Zacatecas. Tetewa is the wife of Tayau, the supreme sun God, and is associated with the moon, the rain and the west (Dahlgren de Jordan 1994).

Comments. As indicated in the diagnosis, the new species is very similar to M. centralis.
In fact, the male genitalia of both species are almost identical. Both species belong to a group of Megalopta s. str. whose males exhibit a distinct, globular, spongy structure dorsally on the metepisternum (Fig. 4). Eickwort (1969) first noted this bizarre structure but its function remains unknown. He also listed other characters found in that species group, such as the lack of postanal filaments on the proctiger of the male and the smooth and shiny basal area of the propodeum of both sexes.

Despite their morphological similarity, both sexes of $M$. tetewana $\mathrm{n}$. sp. can be reliably separated from $M$. centralis by those characters mentioned in the diagnosis and in the key. Additionally, both species seem to be geographically separated as shown in Fig. 12. Given the type of forest of Chamela (tropical dry forest), the type locality of M. tetewana n. sp., it is likely that this species also occurs

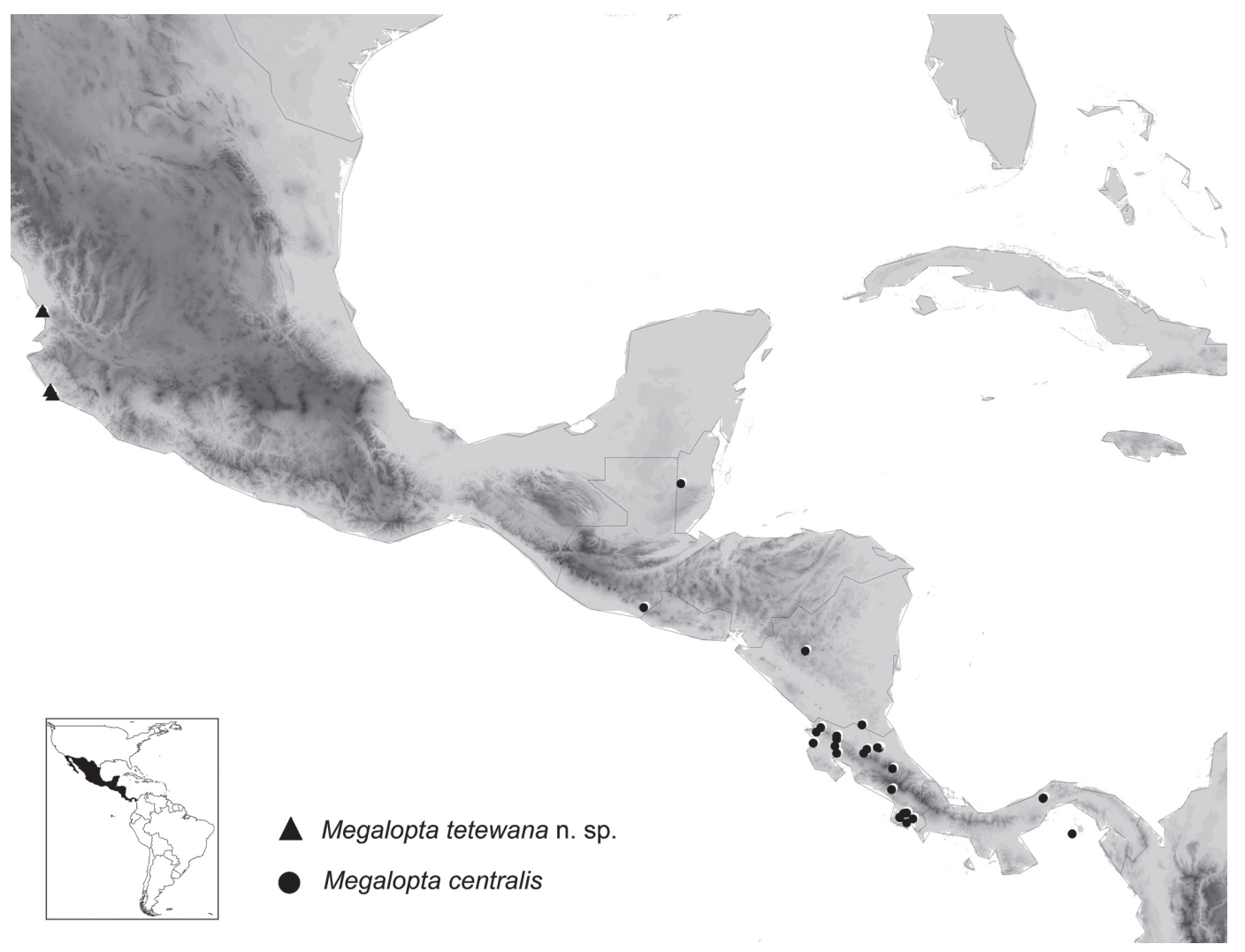

Fig. 12. Geographical distribution of M. tetewana n. sp. and M. centralis in Central America, including Mexico. 
along the Pacific Coast of Mexico, between the states of Sinaloa and Oaxaca, and in some areas in the central depression (the Balsas River) where the same type of forest occurs. Further sampling is required to corroborate the apparent allopatry of these species.

The new species has been collected on flowers of the following species: Caesalpinia eriostachys, Casearia tremula, Croton suberosus, Colubrina triflora, Ipomoea wolcottiana, Iresine sp., Jacaratia mexicana, Jacquemontia sp., Lycianthes sp., Prokia crucis, Serjania brachycarpa and Tabebuia rosea (Ayala 2004).

\section{Megalopta (Noctoraptor) huaoranii n. sp.}

(Figs. 13-15)

Diagnosis. This species resembles $M$. byroni in the basal area of labrum weakly bicallose, scutum and metanotum convex, and yellowish tarsi (Fig. 13); it can be separated from that species by the coarse and sparse punctures on the hypoepimeral area (Fig. 14) and the striae on the preomaular area, metepisternum dorsally and lateral surface of propodeum ventrally. The clypeus, supraclypeal area, vertex, gena, disc of scutum, and terga are also more densely punctate than in $M$. byroni.
Female. Body length $14.8 \mathrm{~mm}$; forewing length $11.7 \mathrm{~mm}$. Structure. Head $1.2 \mathrm{x}$ wider than long; mandible slender, simple, gently curved toward apex; basal area of labrum weakly bicallose at apex; clypeus about 3.0x broader than long, with distal third projecting below lower tangent of compound eye; interalveolar distance $\sim 0.8 \mathrm{x}$ alveolorbital distance; interocellar distance as long as ocelloccipital distance, 1.3x OD; ocellocular distance as long as $\mathrm{OD}$; scape 6.0x longer than broad; pedicel longer than broad; F1 about as long as broad, as long as pedicel, slightly longer than F2, F3-F10 each longer than wide, each longer than F1 and F2 individually; F10 longest; compound eye about $2.3 x$ longer than maximum width in profile view, $1.2 \mathrm{x}$ wider than maximum width of gena in profile; gena gently protuberant posteriorly. Inner hind tibial spur with eight teeth (not including apex as a tooth), basal four slender and smaller than remaining teeth (Fig. 15). Coloration. Mandible and labrum brown; clypeus, supraclypeal area dark brown with weak brassy and metallic violet reflections, remaining areas of face and gena with mainly brassy reflections; scape black, antennal flagellum ferruginous. Mesosoma mainly brassy as on face, with weak metallic violet reflections on disc of scutum; coxae, trochanters and
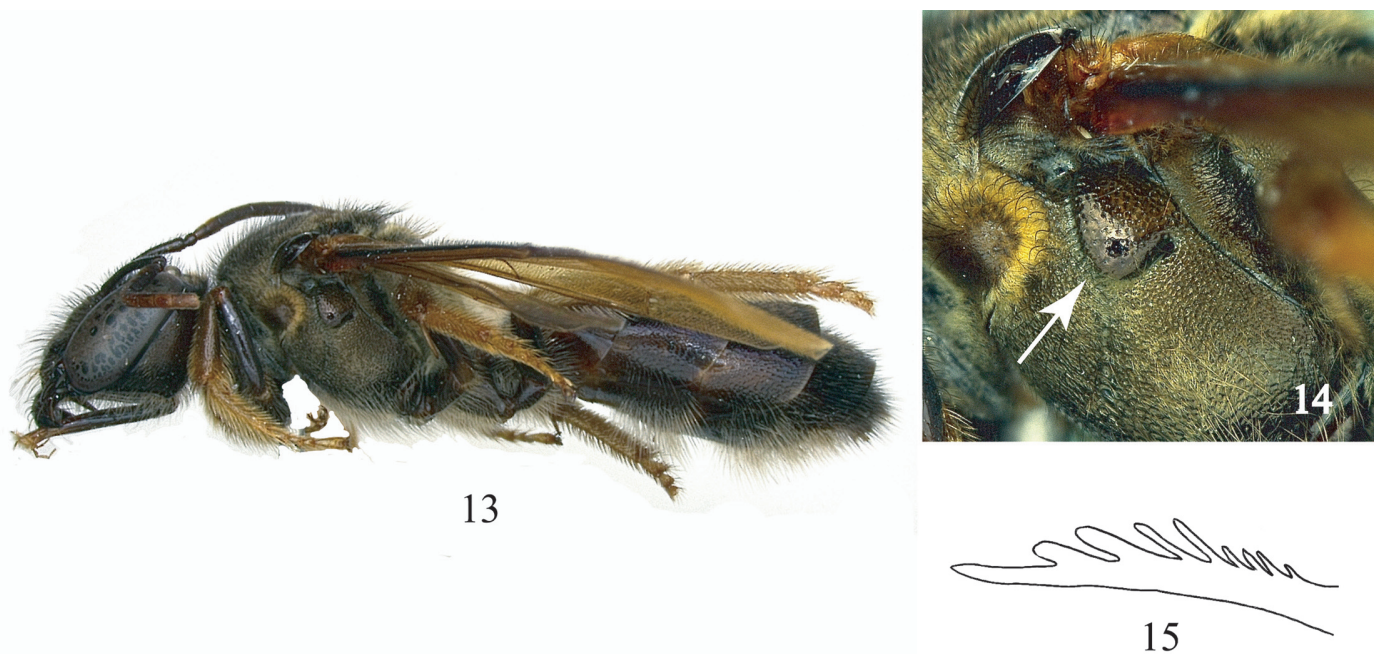

Figs. 13-15. Megalopta huaoranii n. sp., female. 13, lateral habitus. 14, hypoepimeral area indicated by the arrow. 15, hind tibial spur. 
femora dark brown, tibiae light brown and tarsi yellow; tegula brown; wings yellow, veins and stigma light orange to yellow, except for vein $\mathrm{R}$ dark brown. Metasomal terga dark brown with weak brassy and metallic violet reflections; basal and apical margins of T3 to T5 also with weak metallic blue reflections. Pubescence. Head and mesosoma with two types of hairs: sparse, long (1.5-2.0x OD), erect, simple or poorly branched hairs and denser, short $(\leq 0.5 \mathrm{x}$ OD), semi-erect, golden to pale branched hairs. Face except for distal half of clypeus, vertex, upper gena, pronotal lobe, mesepisternum dorsally, scutum, scutellum, and metanotum with brown erect hairs; remaining areas of head and mesosoma (including legs) with erect hairs golden to pale; erect hairs longer on distal half of clypeus, hypostomal area, and mesepisternum, sides of propodeum and metanotum; semi-erect hairs sparse on disc of scutum and hypoepimeral area, dense on lateral surface of propodeum; basal area of propodeum hairless. Terga densely covered (integument still visible among hairs) with simple, semi-erect, short $(\leq 0.5 x$ OD), golden hairs; $T 1$ with long (1.0x OD), erect golden hairs on anterior surface; disc of $\mathrm{T} 1$ and remaining terga with sparse, erect, dark brown hairs, hairs longer and darker on T4 and T5; sterna with longer (2.0x OD), simple, pale hairs. Punctation. Clypeus and supraclypeal area with sparse (2-3x PW), large punctures, integument smooth, shiny between punctures; remaining areas of face, vertex and gena coarsely and densely punctate, punctures finer and sparser on gena, integument otherwise smooth; hypostomal area minutely imbricate between sparse punctures. Pronotum laterally striate; scutum densely, coarsely punctate laterally, sparsely (1-2x PW), weakly punctate on disc centrally, integument imbricate between punctures; scutellum with finer punctures than on scutum, integument smooth between punctures; metanotum minutely, more densely punctate than on scutellum, integument otherwise smooth; preomaular area striate, hypoepimeral area coarsely and sparsely punctate (1-2x $\mathrm{PW})$; mesepisternum strongly, densely punctate; metepisternum striate dorsally; basal area of propodeum nearly smooth; propodeum on basal third as on scutellum, minutely, densely punctate with smooth integument between punctures; on lateral surface finely, densely punctate dorsally, striate ventrally, posterior surface of propodeum rugulose. Dorsal surface of T1 and T2 to T4 finely, densely punctate, integument strongly imbricate between punctures; anterior surface of $\mathrm{T} 1$ and disc of T5 sparsely punctate, integument smooth and shiny between punctures; sterna strongly imbricate, especially on S2 and S3.

Holotype. Female. ECUADOR: Napo, Yasuni Res. Sta. 4-9 May 2003, C. Brammer $250 \mathrm{~m}$ M.T. [malaise trap] $0^{\circ} 40.566 \mathrm{~S}, 076^{\circ}$ 23.851 W (BBSL).

Etymology. The specific epithet honors the Huaorani, an indigenous group from the Amazonian region of Ecuador whose ancestral lands are located between the Curaray and Napo rivers.

Comments. The gena of $M$. huaoranii n. sp. is gently protuberant distally unlike the strongly projected gena of M. byroni. The presence of such a projection is highly variable in species of Megalopta s. str. and might also be variable among Noctoraptor species. The space between $\mathrm{T} 2$ and $\mathrm{T} 3$, and $\mathrm{T} 3$ and $\mathrm{T} 4$ on the holotype is distinctly filled with unidentified acari.

\section{Key to the Central American species of Megalopta s. str.}

1. Basal area of propodeum striate, at least medially; posterobasal area of metepisternum in male unmodified, without a distinct, opaque, spongy structure $\ldots \ldots \ldots \ldots \ldots \ldots .2$

-. Basal area of propodeum smooth, not striate at all; posterobasal area of metepisternum in

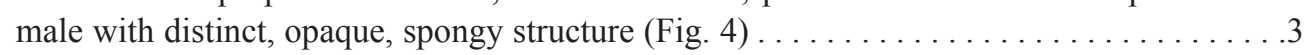


2(1). Head and mesosoma largely metallic green, metasoma light brown; S4 of male with short and broad sublateral notch, not forming a long lateral lobe.......... M. genalis Meade-Waldo

- Head and mesosoma predominantly shiny black to very dark reddish brown, with weak metallic copper-green reflections on face and sides of mesosoma; S4 of male with long, narrow sublateral notch, thus forming a long, distinct lateral lobe .......... atra Engel

3(1). Mesepisternum, scutum, scutellum, and metanotum usually predominantly light brown with weak metallic green reflections; scutum and scutellum largely smooth and shiny, with minute, sparse punctures (Fig. 2); pronotum with a strong lateral carina in normal-headed females

M. tetewana $\mathrm{n} . \mathrm{sp}$.

- Mesepisternum, scutum, scutellum, and metanotum with extensive metallic green reflections; scutum and scutellum more densely punctate (Fig. 1); pronotum usually with weak lateral carina in normal-headed females . . . . . . . . . . . . . . . . . . .

\section{Key to the species of Megalopta subgenus Noctoraptor}

(Modified from Hinojosa-Díaz \& Engel 2003)

1. Basal area of labrum with two distinct calli at apex; tarsi (excluding basitarsi) reddish brown

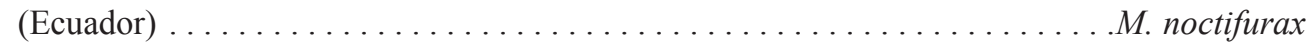

- Basal area of labrum weakly bicallose at apex; tarsi (excluding basitarsi) yellow to yellowish

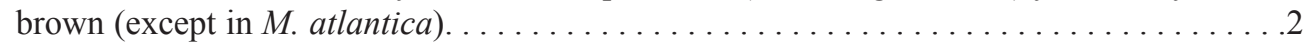

2(1). Scutellum and metanotum flattened, forming relatively uninterrupted surface in lateral view from scutum to posterior border of propodeal basal area $\ldots \ldots \ldots \ldots \ldots \ldots \ldots$

- Scutellum and metanotum convex, both distinctly elevated above the level of each other and relative to the sloping surface of the propodeal basal area $\ldots \ldots \ldots \ldots \ldots \ldots \ldots$

3(2). Disc of terga punctate; basal area of propodeum rugulose; antennal sockets without metallic green reflections; tarsi brown (southeastern Brazil) ................... atlantica

-. Disc of terga impunctate; basal area of propodeum smooth; antennal sockets with metallic green reflections; tarsi yellowish (Guyana) ................... furunculosa

4(2). Hypoepimeral area smooth anteriorly, punctate posteriorly; metepisternum with scattered minute punctures, not striate dorsally; terga shiny with scattered weak punctures (Panama)

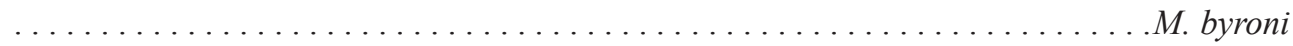

- Hypoepimeral area coarsely and sparsely punctate throughout (Fig. 14); metepisternum striate dorsally; terga dull, strongly imbricate, T1-T3 with dense punctures, stronger on T1

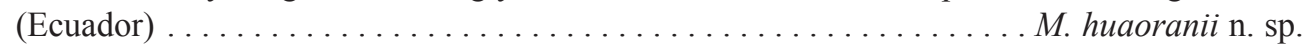

\section{ACKNOWLEDGMENTS}

Claus Rasmussen, Cecilia Waichert, and three anonymous reviewers made significant comments that helped to improve this note; Harold Ikerd (BBSL) produced the map and assisted with the database; Charles D. Michener, Michael S. Engel, Zack Falin, and Jennifer Thomas provided access to the bee collection at SEMC; Wojciech Pulawski at CAS for lending us the Megalopta specimens from Nicaragua. This study was supported in part by National Science Foundation grant DEB-0742998.

\section{RESUMEN}

Megalopta Smith, 1853, es un género Neotropical de abejas nocturnas o crepusculares. Dos subgéneros son reconocidos con la mayoría de las 30 especies ubicadas en el subgénero nominal. Las especies de Megalopta s. 
str. son más comúnmente recolectadas que las especies de Noctoraptor Engel et al. 1997, todas probablemente parásitas de Megalopta s. str. Aquí se describen dos especies nuevas de Megalopta: M. (Megalopta) tetewana, n. sp., de México y M. (Noctoraptor) huaoranii, n. sp., de Ecuador. Se presentan claves de identificación para las especies de Megalopta s. str. de América Central y las especies del subgénero parásito Noctoraptor.

Palabras clave: Augochlorini, Apoidea, parásitos, Centroamérica, claves, sistemática.

\section{REFERENCES}

Ayala, R. 1989. La fauna de abejas silvestres (Hymenoptera: Apoidea) de Chamela, Jalisco. México. Folia Entomol. Mex. 77: 395-493.

Ayala, R. 2004. Fauna de abejas silvestres (Hymenoptera: Apoidea), p. 193-219. In A.N. García-Aldrete \& R. Ayala (eds.). Artrópodos de Chamela. Instituto de Biología, Universidad Nacional Autónoma de México, México.

Biani, N. \& W.T. Wcislo. 2007. Notes on the reproductive morphology of the parasitic bee Megalopta byroni (Hymenoptera: Halictidae), and a tentative new host record. J. Kansas Entomol. Soc. 80: 392-394.

Dahlgren de Jordan, B. 1994. Los Coras de la Sierra de Nayarit. Instituto de Biología, Universidad Nacional Autónoma de México, México.

Eickwort, G.C. 1969. A comparative morphological study and generic revision of the augochlorine bees (Hymenoptera: Halictidae). Univ. Kans. Sci. Bull. 48: 325-524.
Engel, M.S. 2000. Classification of the bee tribe Augochlorini (Hymenoptera: Halictidae). Bull. Am. Mus. Nat. Hist. 250: 1-90.

Engel, M.S. 2006. A new nocturnal bee of the genus Megalopta, with notes on other Central American species (Hymenoptera: Halictidae). Mitt. Internat. Entomol. Ver. 31: 37-49.

Engel, M.S., R.W. Brooks, \& D. Yanega. 1997. New genera and subgenera of augochlorine bees (Hymenoptera: Halictidae). Bull. Nat. Hist. Mus. Univ. Kans. 5: 1-21.

Hinojosa-Díaz, I.A. \& M.S. Engel. 2003. Megalopta (Noctoraptor) furunculosa sp. n., a new nocturnal, cleptoparasitic bee from Guyana (Hymenoptera: Halictidae). Fol. Heyrovskiana 11: 137-141.

Michener, C.D. 2007. The Bees of the World. Johns Hopkins University, Baltimore, Maryland, USA.

Moure, J.S. 2007. Augochlorini Beebe, 1925, p. 759-872. In J.S. Moure, D. Urban \& G.A.R. Melo (eds.). Catalogue of Bees (Hymenoptera, Apoidea) in the Neotropical Region. Sociedad Brasileira de Entomologia, Curitiba, Brazil (also available online: http://moure. cria.org.br/catalogue).

Santos, L.M. \& F.A. Silveira. 2009. Taxonomic notes on Megalopta Smith, 1853 (Hymenoptera: Halictidae: Augochlorini) with a synopsis of the species in the state of Minas Gerais, Brazil. Zootaxa 2194: 1-20.

Wcislo, W.T., L. Arneson, K. Roesch, V.H. Gonzalez, A. Smith \& H. Fernandez. 2004. The evolution of nocturnal behaviour in sweat bees, Megalopta genalis and M. ecuadoria (Hymenoptera: Halictidae): an escape from competitors and enemies? Biol. J. Linn. Soc. $83: 377-387$. 
